\title{
Uso da vegetação nativa pela população local no município de Ingaí, MG, Brasil ${ }^{1}$
}

\author{
Rejane Tavares BotreP, , Luciene Alves Rodrigues ${ }^{3}$, Laura Jane Gomes ${ }^{4}$, Douglas Antônio de Carvalho ${ }^{5}$ e \\ Marco Aurélio Leite Fontes ${ }^{6}$
}

Recebido em 13/02/2004. Aceito em 22/07/2005.

\begin{abstract}
RESUMO - (Uso da vegetação nativa pela população local no município de Ingaí, MG, Brasil). O objetivo do presente estudo foi realizar um levantamento etnobotânico no município de Ingaí, MG, para se conhecer os usos que a população local atribui à vegetação nativa da região e investigar se tais usos se destinam à subsistência ou comercialização. O levantamento etnobotânico foi conduzido como estudo de caso, na área urbana e periurbana do município. Foram realizadas entrevistas com 17 moradores utilizando questionários semiestruturados. A partir destas entrevistas foi possível classificar as espécies em quatro categorias de uso: medicinal, lenha, madeireiro (construção civil e fabricação de móveis) e diversos usos (artesanato, alimentação, ferramentas, etc.). Os dados foram analisados por meio de descrições qualitativas e quantitativas (índices de diversidade de Shannon - H'- e equabilidade de Pielou - J'). Para análise de importância relativa das espécies indicadas para uso medicinal, foram utilizadas a concordância quanto ao uso principal (CUP), o fator de correção (FC) e a concordância quanto ao uso principal corrigida (CUPc). Foram atribuídos usos a 144 espécies coletadas, identificadas e distribuídas nos hábitos de arbórea, arbustiva, herbácea e trepadeira. No município, existe a comercialização de espécies vegetais, em sua maior parte para uso lenheiro e feitio de moirões. Quanto à importância relativa das espécies, aquelas que apresentaram maiores valores de CUP e CUPc, sugerem maior potencial para estudos farmacológicos: Ilex cerasifolia Reisseck e Solanum lycocarpum A. St.-Hil, que apresentaram valores integrais para os dois índices. O índice de diversidade de Shanonn encontrado para as plantas citadas foi considerado alto, sugerindo que a população utiliza uma grande parcela da diversidade local, na maior parte, apenas para fins de subsistência.
\end{abstract}

Palavras-chave : etnobotânica, plantas medicinais, lenha, espécie madeireira

\begin{abstract}
Use of native vegetation by the local population in Ingaí municipacity, Minas Gerais State, Brazil). The purpose of the present study was to carry out an ethnobotanyc survey in the municipality of Ingaí, Minas Gerais State, Brazil, to investigate the use of native vegetation resources by the local population. The survey was carried out, as a case study, in the urban and peripheral areas of Ingaí town. A sample of 17 inhabitants was interviewed using semi-structured questionnaires. The interviews allowed the classification of the plant species into four categories of use: medicinal, firewood, wood (for buildings and furniture), and miscellaneous uses (handicraft, food, tools, et cetera). Data analyses were performed through qualitative and quantitative (indices the Shannon diversity H' - and Pielou evenness - J') descriptions. The principal use concordance (PUC), the correction factor (CF), and the corrected principal use concordance (PUCc) were used to analysis the relative importance of the species indicated for medicinal use. Modes of use were ascribed to 144 collected and identified species, which were distributed into the following habits: trees, shrubs, herbs, and climbers. The trade of native species exists in Ingaí, mostly to meet the demand for wood and fence posts. The species with the highest relative importance, in terms of PUC and PUCc values, were Ilex cerasifolia Reisseck and Solanum lycocarpum A. St.-Hil, suggesting a high potential for pharmacological studies. The local population holds a detailed knowledge of the native vegetation and uses this knowledge as a basis for a diversified utilisation of the flora, most of which intended only to subsistence purposes.
\end{abstract}

Key words: ethnobotany, medicinal plants, firewood, wood specie

\section{Introdução}

A região Sul de Minas Gerais está entre os locais de ocupação mais antiga do Brasil e seu histórico mostra que a economia local sempre se baseou na exploração dos recursos naturais. A região passou por quatro ciclos econômicos que se complementavam ou se alternavam: ciclo do ouro, agropastoril, do café e da

\footnotetext{
1 Parte da Dissertação de Mestrado da primeira Autora

2 Rua João Fischer, 260, Bairro Morumbi, CEP 13420-450, Piracicaba, SP, Brasil

3 Rua Prefeito Antônio Cândido, 41, Centro, CEP 39280-000, Buritizeiro, MG, Brasil (luciene.rodrigues@ibama.gov.br)

4 Universidade Federal de Sergipe, Departamento de Engenharia Agronômica, Av. Marechal Rondon, s/n, CEP 49100-000, Sergipe, PE, Brasil

5 Universidade Federal de Lavras, Departamento de Biologia, CEP 37200-000, Lavras, MG, Brasil

6 Universidade Federal de Lavras, Departamento de Ciências Florestais, CEP 37200-000, Lavras, MG, Brasil

7 Autor para correspondência: rtbotrel@yahoo.com.br
} 
industrialização. Como resultado, a paisagem atual é formada por mosaicos de remanescentes vegetais, áreas urbanas e áreas agropastoris.

Embora os fragmentos vegetais ocupem áreas restritas e, algumas vezes, isoladas entre si, possuem uma alta diversidade florística e são representativos da flora da região, como mostram os estudos realizados na Reserva Biológica de Poço Bonito (Oliveira Filho et al. 1994; Oliveira Filho \& Fluminhan Filho 1999), na Reserva Florestal da Universidade Federal de Lavras (Oliveira Filho, Scolforo \& Mello 1994), ambas no município de Lavras, e o estudo realizado na mata da ilha (Botrel et al. 2002), no município de Ingaí, entre outros.

No entanto, apesar de diversos estudos terem sido realizados sobre a flora da região e dos processos ecológicos que determinam a estrutura das comunidades (Oliveira Filho et al. 1997; Oliveira Filho et al. 1994; Vilela et al. 2000; Nunes et al. 2003; Souza et al. 2003), pouco se conhece sobre a relação que as populações locais têm com os remanescentes vegetais. Neste sentido, o conhecimento popular sobre o uso das espécies vegetais nativas pode contribuir para a conservação destes ecossistemas no que diz respeito a adoção de práticas de manejo, além de contribuir para o resgate e preservação da cultura popular. Sendo assim, este estudo teve como objetivo geral investigar o conhecimento que a população urbana de Ingaí tem sobre a vegetação nativa; e, como objetivos específicos a identificação das espécies usadas pela população local e seus diferentes usos.e a investigação da existência de exploração seletiva de espécies vegetais e se esta ocorre para fins de subsistência ou comercialização.

\section{Material e métodos}

Área de estudo - O estudo etnobotânico foi realizado na área urbana e periurbana do município de Ingaí, localizado ao sul de Minas Gerais, nas coordenadas $21^{\circ} 40^{\prime} \mathrm{S}$ e $44^{\circ} 91^{\prime} \mathrm{W}$ (Fig. 1). A área total do município é de $307,5 \mathrm{~km}^{2}$ e sua altitude média de $951 \mathrm{~m}$. Segundo a Fundação João Pinheiro (1998), a população total do município consiste em 2.419 habitantes, divididos em 1.412 na zona urbana e 1.007 na rural.

O clima regional é do tipo Cwb de Köppen, caracterizado por verões úmidos e invernos secos (Eidt, 1968) e de acordo com a Estação Meteorológica de Lavras, MG, com temperatura média anual de $19,61^{\circ} \mathrm{C}$ e precipitação média anual de $1.517 \mathrm{~mm}$.

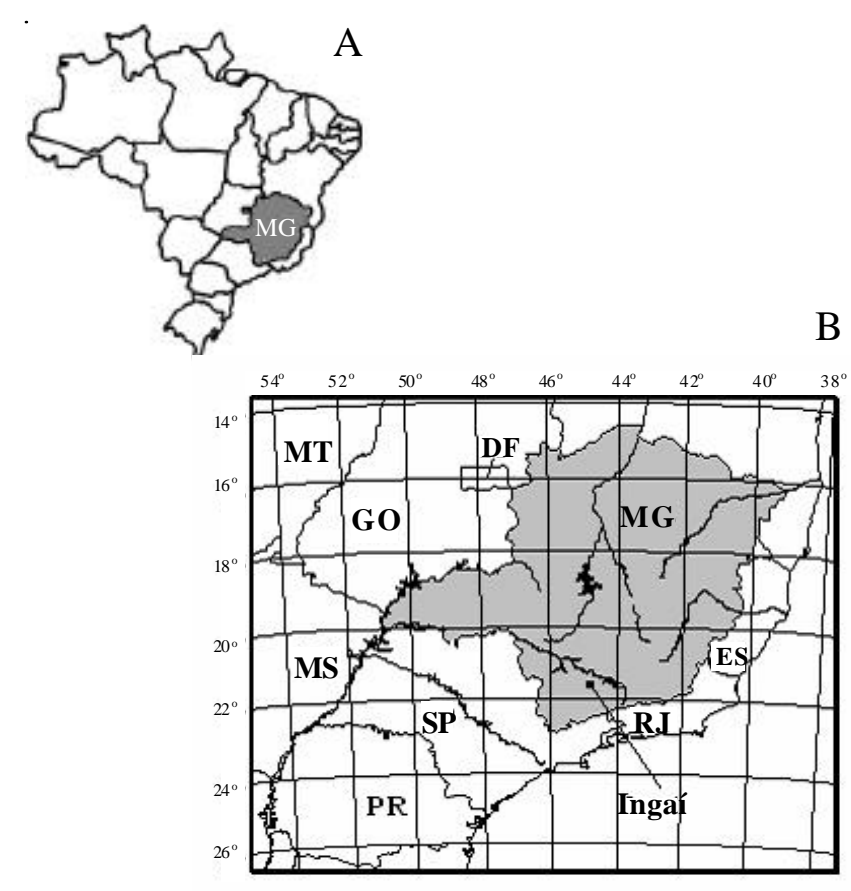

Figura 1. A. Situação geográfica do Estado de Minas Gerais no Sudeste do Brasil e B. Município de Ingaí, MG.

A vegetação nativa da região engloba áreas de cerrado, campos cerrados, matas de galeria, matas de encosta e campos rupestres (Queiroz et al. 1980). Existe uma limitação agrícola relacionada ao solo e à topografia que restringe a mecanização (Queiroz et al. 1980). A vegetação natural do município forma um mosaico juntamente com pastagens e áreas cultivadas (ativas ou abandonadas).

Atualmente a economia do município se baseia na criação de gado leiteiro, responsável por $92,6 \%$ do ICMS total arrecadado. A produção cafeeira também possui um importante papel na economia local, pois gera empregos diretos e indiretos durante a colheita, que é concentrada entre os meses de julho a outubro. Método de estudo e coleta de dados - Este trabalho trata-se de um estudo de caso, método que possui a vantagem de permitir examinar em profundidade o desenvolvimento de ações em seus próprios cenários (Alencar \& Gomes 1998; Triviños 1987).

Os dados foram coletados a partir de uma amostragem intencional não probabilística (Alencar \& Gomes 1998), por meio da qual os informantes foram selecionados de acordo com indicações de membros da própria comunidade. Foram entrevistados 17 moradores do município, divididos em oito homens e nove mulheres, com idade entre 45 e 75 anos, durante o período compreendido entre os meses de julho e 
outubro/2000. Em relação às principais atividades econômicas exercidas pelos entrevistados, estes se dividiam em dois artesões, quatro raizeiros, cinco lenheiros e três agricultores. Os entrevistados restantes não se enquadravam em nenhuma das categorias, sendo um deles comerciante e os outros aposentados. Para preservação da identidade dos entrevistados foram utilizados números de 1 a 17 para a identificação na divulgação dos resultados.

A coleta dos dados se deu por meio de entrevistas baseadas em um questionário semi-estruturado no qual constavam os dados gerais dos entrevistados, além de informações a respeito das plantas nativas citadas e categorias de uso atribuídas a elas. Tal questionário permitiu aos entrevistados manifestar suas opiniões, seus pontos de vista e seus argumentos, conforme recomendação de Alencar \& Gomes (1998).

Quatro informantes, de acordo com sua disponibilidade, foram escolhidos para acompanhar as coletas de material botânico em remanescentes vegetais e área antrópicas (pastagens e áreas de cultivo abandonadas) próximas à cidade. Os locais de coleta foram escolhidos pelos informantes. Foram coletadas e identificadas espécies arbóreos, arbustivas, herbáceas e trepadeiras. O material botânico foi preparado no Herbário do Departamento de Biologia da Universidade Federal de Lavras (Herbário ESAL) e a coleção testemunha incorporada ao acervo do mesmo. A identificação deste material foi realizada com a utilização de coleções botânicas já existentes e também por meio de consultas à literatura, à especialistas e à coleções dos Herbários do Jardim Botânico do Rio de Janeiro (RB), do Instituto de Botânica de São Paulo (SP) e da Universidade Estadual de Campinas (UEC). A classificação botânica baseou-se no sistema proposto pelo Angiosperm Phylogeny Group (APG) (1998). As espécies exóticas foram excluídas do trabalho. Considerou-se espécie exótica aquela que não ocorre naturalmente na região, de acordo com a literatura.

A partir dos dados obtidos foram calculados os índices de diversidade de Shannon e equabilidade de Pielou. O primeiro permite que se verifique o quanto da diversidade local é usada pela população e o segundo avalia a existência ou não de dominância no uso de algumas espécies. Para a comparação entre a diversidade de uso da vegetação pela população e a diversidade de espécies locais foi utilizado o estudo florístico e estrutural realizado por Botrel et al. (2002) na Mata da Ilha, remanescente de aproximadamente 17 ha localizado a cerca de $3 \mathrm{~km}$ da área urbana do município, às margens do rio Ingaí. Essa mata possui um gradiente ambiental, proporcionando diversos microhabitats, devido a variações no tipo de solo, fertilidade, umidade e relevo. Podemos encontrar desde espécies típicas de áreas ciliares até espécies de terra firme, incluindo floresta semidecídua e cerrado.

Para a categoria medicinal, além da descrição qualitativa dos resultados, foi calculada a importância relativa das espécies utilizadas pela comunidade local, de acordo com Amorozo e Gély (1988), por meio da concordância quanto ao uso principal (CUP), fator de correção (FC) e concordância quanto ao uso principal corrigida (CUPc). Os referidos índices são baseados no número de informantes que citaram determinada espécie e os resultados indicam aquelas com potencial para estudos farmacológicos.

\section{Resultados e discussão}

Foram coletados 143 espécimes, dos quais 138 foram identificados quanto à espécie, quatro quanto ao gênero e uma quanto à família (Tab. 1). No total, foram registradas 49 famílias botânicas e 108 gêneros, divididos em diferentes hábitos: arbóreos (100 espécies), arbustivas (16), herbáceas (20) e trepadoras (7).

A família de maior riqueza florística foi Fabaceae, com $20(13,98 \%)$ espécies citadas, distribuídas em hábitos arbustivo e arbóreo (21). Desta família foram citadas espécies de uso medicinal (Stryphnodendron adstringens (Mart.) Cov. Erythrina falcata Benth.), madeireiro (Machaerium hirtum (Vell.) Stellfeld, Machaerium nictitans (Vell.) Benth., Machaerium stipitatum (DC.) Vogel, Machaerium villosum Vogel), para lenha (Sebastiania commersoniana (Baillon) Smith \& Dows, Copaifera langsdorffii Desf.) e também para outros usos, como a construção de carros de boi (Bowdichia virgilioides Kunth, Platycyamus regnellii Benth.), sendo algumas das espécies próprias para mais de um uso.

As famílias Myrtaceae, Asteraceae e Rubiaceae contribuíram com 13 (9,09\%), dez (6,99\%) e nove $(6,29 \%)$ espécies, respectivamente, para a riqueza florística. A família Myrtaceae destacou-se como sendo aquela com o maior número de espécies citadas como lenha (7). Em relação às espécies arbóreas e herbáceas que representaram a família Rubiaceae, quatro apresentaram uso medicinal exclusivo e as restantes foram indicadas para lenha, construção civil e diversos usos. A Família Asteraceae apresentou espécies de todos os hábitos e seis delas foram indicadas para uso medicinal (Alomia fastigiata Benth., Baccharis 
Tabela 1. Lista das espécies botânicas coletadas, citadas pelos entrevistados durante o levantamento etnobotânico no município de Ingaí, MG, Brasil com seus respectivos nomes vulgares, hábitos, usos, destino e registro no Herbário ESAL.

\begin{tabular}{|c|c|c|c|c|c|}
\hline Família/Espécie & Nome vulgar & Hábito & Uso & Destino & $\begin{array}{l}\text { Registro } \\
\text { ESAL }\end{array}$ \\
\hline \multicolumn{6}{|l|}{ ALISMATACEAE } \\
\hline $\begin{array}{l}\text { Echinodorus grandiflorus Mitch. } \\
\text { AMARANTACEAE }\end{array}$ & chapéu-de-couro & Herbáceo & M1 & $\mathrm{S}$ & 16717 \\
\hline \multicolumn{6}{|l|}{ ANACARDIACEAE } \\
\hline Anacardium humile A. St.-Hil. & caju & Arbustivo & M1 & $\mathrm{S}$ & 16719 \\
\hline Lithraea molleoides (Vell.) Engler & aroeira & Arbóreo & $\mathrm{L}$ & $\mathrm{S}$ e C & 16770 \\
\hline Schinus terebinthifolius Raddi & $\begin{array}{l}\text { aroeira-periquita; } \\
\text { aroeira-da-beira-do-rio }\end{array}$ & Arbóreo & $\mathrm{L}$ & $\mathrm{S}$ & 16722 \\
\hline Tapirira obtusa (Benth.) Mitchell & peito-de-pomba & Arbóreo & $\mathrm{L}$ & $\mathrm{S}$ e C & 16721 \\
\hline \multicolumn{6}{|l|}{ ANNONACEAE } \\
\hline Rollinia emarginata Schltdl. & $\begin{array}{l}\text { araticunzinho-da- } \\
\text { beira-do-rio }\end{array}$ & Arbóreo & M3 & - & 16725 \\
\hline R. laurifolia Schltdl. & $\begin{array}{l}\text { araticum-macaco; } \\
\text { só-brasil; mutamba }\end{array}$ & Arbóreo & M3 & - & 16726 \\
\hline R. sericea (R.E. Fries) R.E. Fries & araticum & Arbóreo & $\mathrm{L}$ & $\mathrm{S}$ & 16727 \\
\hline \multicolumn{6}{|l|}{ APOCYNACEAE } \\
\hline Aspidosperma parvifolium A. DC. & congonha-do-mato & Arbóreo & M3 & - & 16731 \\
\hline A. ramiflorum Müll. Arg. & peroba-branca & Arbóreo & M3 & - & 16732 \\
\hline A. spruceanum Benth. & guatambu-canário & Arbóreo & M3 & - & 16733 \\
\hline \multicolumn{6}{|l|}{ AQUIFOLIACEAE } \\
\hline Ilex cerasifolia Reisseck & $\begin{array}{l}\text { congoinha; congoinha- } \\
\text { miúda; congonha-da- } \\
\text { serra }\end{array}$ & Arbóreo & M1 & $\mathrm{S}$ & 16852 \\
\hline \multicolumn{6}{|l|}{ ARALIACEAE } \\
\hline Dendropanax cuneatus (DC.) Decne \& Planchon & $\begin{array}{l}\text { mandioca-do-mato; } \\
\text { mandiocão }\end{array}$ & Arbóreo & APP & $\mathrm{S}$ & 16736 \\
\hline \multicolumn{6}{|l|}{ ARISTOLOCHIACEAE } \\
\hline Aristolochia gilbertti Hook & milhomem & Trepadeira & M1 & $\mathrm{S}$ & 16737 \\
\hline \multicolumn{6}{|l|}{ ASTERACEAE } \\
\hline Alomia fastigiata Benth & mata-pasto & Herbáceo & M1 & $\mathrm{S}$ & 16738 \\
\hline Baccharis dentata (Vell.) G.M. Barroso & alecrim-do-grande & Arbustivo & M1 & $\mathrm{S}$ & 16776 \\
\hline B. dracunculifolia DC. & alecrim; alecrim-do-campo & Arbustivo & M1 & $\mathrm{S}$ & 16777 \\
\hline B. trimera (Less.) DC. & carqueja & Herbácea & M1 & $\mathrm{S}$ & 16739 \\
\hline Eremanthus erythropappus (DC.) MacLeish & candeinha & Arbóreo & M2 & $\mathrm{C}$ & 16740 \\
\hline E. incanus (Less.) Less. & candeia; candeião & Arbóreo & M2 & $\mathrm{C}$ & \\
\hline Mikania hirsutissima D.C. & cipó-cabeludo (legítimo) & Trepadeira & M1 & $\mathrm{S}$ & 16742 \\
\hline M. sessilifolia D.C. & orelha-de-onça & Herbáceo & M1 & $\mathrm{S}$ & 16743 \\
\hline Vernonia diffusa Less. & cambará & Arbóreo & $\mathrm{CF}$ & - & 16745 \\
\hline$V$. polyanthes Less & assa-peixe & Arbustivo & $\mathrm{L}$ & $\mathrm{S}$ & 16746 \\
\hline \multicolumn{6}{|l|}{ BIGNONIACEAE } \\
\hline Cybistax antisyphillitica Mart. & cinco-folhas & Arbóreo & M1 & $\mathrm{S}$ & 16747 \\
\hline Jacaranda decurrens Cham. & carobinha & Arbustivo & M1 & $\mathrm{S}$ & 16748 \\
\hline Jacaranda sp. & carobinha-do-campo & Arbustivo & M1 & $\mathrm{S}$ & 16749 \\
\hline Pyrostegia venusta Miers. & $\begin{array}{l}\text { cipó-de-são-joão; } \\
\text { cipó-vermelho }\end{array}$ & Trepadeira & M1 & $\mathrm{S}$ & 16750 \\
\hline Tabebuia ochracea (Cham.) Standl. & ipê-do-campo & Arbóreo & M3 & - & 16752 \\
\hline T. serratifolia (Vahl) Nichols. & ipê-branco & Arbóreo & M3 & - & 16753 \\
\hline \multicolumn{6}{|l|}{ BUDDLEJACEAE } \\
\hline Bluddleja brasiliensis Jacq. & baibasso & Herbáceo & M1 & $\mathrm{S}$ & 16757 \\
\hline \multicolumn{6}{|l|}{ BURSERACEAE } \\
\hline Protium heptaphyllum (Aubl.) March. & amescla-vermelha & Arbóreo & $\mathrm{CC}$ & - & 16758 \\
\hline P. widgrenii Engler & amescla-branca & Arbóreo & $\mathrm{CC}$ & - & 16760 \\
\hline
\end{tabular}


Tabela 1 (continuação)

\begin{tabular}{|c|c|c|c|c|c|}
\hline Família/Espécie & Nome vulgar & Hábito & Uso & Destino & $\begin{array}{l}\text { Registro } \\
\text { ESAL }\end{array}$ \\
\hline \multicolumn{6}{|l|}{ CECROPIACEAE } \\
\hline \multicolumn{6}{|l|}{ CELASTRACEAE } \\
\hline $\begin{array}{l}\text { Austroplenckia populnea (Reisseck) Lundell } \\
\text { CHENOPODIACEAE }\end{array}$ & perereca-do-campo & Arbóreo & M1 & $\mathrm{S}$ & 16761 \\
\hline $\begin{array}{l}\text { Chenopodium ambrosioides } \mathrm{L} \text {. } \\
\text { CLUSIACEAE }\end{array}$ & erva-santa-maria & Herbáceo & M1 & $\mathrm{S}$ & $\begin{array}{l}16774 \\
16775\end{array}$ \\
\hline \multicolumn{5}{|l|}{ CONNARACEAE } & 16766 \\
\hline Lamanonia ternata Vell. & açoita-cavalo (vermelho) & Arbóreo & $\mathrm{CC}$ & - & 16769 \\
\hline $\begin{array}{l}\text { CONVOLVULACEAE } \\
\text { não identificada }\end{array}$ & cipó-cabeludo & Trepadeira & M1 & $\mathrm{S}$ & \\
\hline \multicolumn{6}{|l|}{ DILLENIACEAE } \\
\hline Davilla rugosa Poir. & cipó-caboclo & Trepadeira & M1 & $\mathrm{S}$ & 16778 \\
\hline $\begin{array}{l}\text { Doliocarpus dentatus (Aubl.) Standl. } \\
\text { EBENACEAE }\end{array}$ & cipó-caboclo & Trepadeira & M1 & $\mathrm{S}$ & 16793 \\
\hline \multicolumn{6}{|l|}{ EUPHORBIACEAE } \\
\hline Actinostemon concolor (Sprengel) Müll.Arg. & batinga; catiguá-de-espinho & Arbóreo & CB; FM; L e CC & $\mathrm{S}$ & 16782 \\
\hline Croton antisyphiliticus Mart. ex M. Arg. & curraleira & Arbóreo & M1 & $S$ & 16794 \\
\hline C. floribundus Sprengel & capixingui & Arbóreo & M3 & - & 16779 \\
\hline C. urucurana Baillon & sangra-d'água & Arbóreo & $\mathrm{CC}$ & - & 16784 \\
\hline Hyeronima ferruginea Tul. & vermelhão-do-mato & Arbóreo & $\mathrm{CC}$ & - & 16785 \\
\hline Pera obovata Baill. & fruta-de-jacu; marmelinho & Arbóreo & $\mathrm{CC} ; \mathrm{L}$ & $\mathrm{S}$ e $\mathrm{C}$ & \\
\hline $\begin{array}{l}\text { Sebastiania commersoniana (Baillon) } \\
\text { Smith \& Dows }\end{array}$ & $\begin{array}{l}\text { bertanha; leiteirinha-da- } \\
\text { beira-do-córrego; leiteira }\end{array}$ & Arbóreo & $\mathrm{CC} ; \mathrm{L}$ & $\mathrm{S}$ & 16789 \\
\hline \multicolumn{6}{|l|}{ FABACEAE CAESALPINIOIDEAE } \\
\hline Bauhinia holophila (Stend.) Bong & unha-de-boi; unha-de-vaca & Arbóreo & M1 & $S$ & 16814 \\
\hline B. longifolia (Bongard) Steudel & $\begin{array}{l}\text { unha-de-boi-do-mato; } \\
\text { espinho-agulha }\end{array}$ & Arbóreo & AP & $\mathrm{S}$ & 16815 \\
\hline Copaifera langsdorffii Desf. & $\begin{array}{l}\text { copaiba; óleo-amarelo; } \\
\text { óleo-vermelho }\end{array}$ & Arbóreo & $\mathrm{CC} ; \mathrm{CB}$ & - & 16817 \\
\hline $\begin{array}{l}\text { Senna occidentalis (L.) Link (=Cassia } \\
\text { occidentalis L.) }\end{array}$ & fedegoso & Arbustivo & M1 & $\mathrm{S}$ & 16822 \\
\hline \multicolumn{6}{|l|}{ FABACEAE FABOIDEAE } \\
\hline Andira fraxinifolia Benth. & argilim & Arbóreo & $\mathrm{CC}$ & - & 16834 \\
\hline Bowdichia virgilioides H.B.K. & sucupira & Arbóreo & $\begin{array}{l}\mathrm{M} 1 ; \mathrm{CC} \text { e } \\
\mathrm{M} 3 ; \mathrm{CB}\end{array}$ & $\mathrm{S}$ & 16835 \\
\hline Erythrina falcata Benth. & sarnão & Arbóreo & M1 & $S$ & 16838 \\
\hline Machaerium hirtum (Vell.) Stellfeld & bico-de-andorinha & Arbóreo & $\mathrm{L} ; \mathrm{CC}$ e $\mathrm{M} 3$ & $\mathrm{~S}$ & 16847 \\
\hline M. nictitans (Vell.) Benth. & bico-de-pato & Arbóreo & $\mathrm{L} ; \mathrm{CC}$ e M3 & $S$ & 16846 \\
\hline M. stipitatum (DC.) Vogel & monjolinho; joão-pelado & Arbóreo & L; CC e M3 & $\mathrm{S}$ & 16845 \\
\hline M. villosum Vogel & jacarandá & Arbóreo & $\mathrm{L} ; \mathrm{CC}$ e M3, G & $S$ & 16844 \\
\hline Platycyamus regnellii Benth. & pereira & Arbóreo & $\mathrm{CB}$ & - & 16843 \\
\hline Platypodium elegans Vogel & jacarandazinho & Arbóreo & $\mathrm{L} ; \mathrm{CC}$ e M3; CB & $\mathrm{S}$ & 16849 \\
\hline \multicolumn{6}{|l|}{ FABACEAE MIMOSOIDEAE } \\
\hline Enterolobium gummiferum (Mart.) Macb. & chapadinho-do-campo & Arbóreo & $\mathrm{CC}$ & - & \\
\hline Rhynchosia phaseoloides (Sw.) DC & tento-miúdo & Arbóreo & M1 & $\mathrm{S}$ & 16954 \\
\hline Inga vera Willd. & angá & Arbóreo & $\mathrm{AL} ; \mathrm{RC}$ & $\mathrm{S}$ & 16828 \\
\hline Leucochloron incuriale (Vell.) Barneby \& Grimes & cortiça & Arbóreo & $\mathrm{R}$ & S & 16829 \\
\hline Mimosa bracaatinga Hoehne & alecrim-da-beira-do-rio & Arbustivo & $\mathrm{CC}$ & - & 16830 \\
\hline $\begin{array}{l}\text { Piptadenia gonoacantha (Mart.) J.F. Macbr. } \\
\text { FABACEAE MIMOSOIDEAE }\end{array}$ & pau-jacaré & Arbóreo & $\mathrm{CC}, \mathrm{L}$ & $\mathrm{S}$ & 16832 \\
\hline $\begin{array}{l}\text { Stryphnodendron adstringens (Mart.) Cov. } \\
\text { FLACOURTIACEAE }\end{array}$ & barbatimão & Arbóreo & $\mathrm{M} 1, \mathrm{CCO}$ e L & $\mathrm{S}$ & 16833 \\
\hline Casearia decandra Jacquin & espeto & Arbóreo & $\mathrm{CC}$ & - & $\begin{array}{l}16795 \\
\text { continu }\end{array}$ \\
\hline
\end{tabular}


Tabela 1 (continuação)

\begin{tabular}{|c|c|c|c|c|c|}
\hline Família/Espécie & Nome vulgar & Hábito & Uso & Destino & $\begin{array}{c}\text { Registro } \\
\text { ESAL }\end{array}$ \\
\hline Casearia lasiophylla Eichler & amburici & Arbóreo & $\mathrm{CC}$ & - & 16796 \\
\hline C. sylvestris Swartz & $\begin{array}{l}\text { erva-lagarto; erva-lagarto- } \\
\text { do-mato }\end{array}$ & Arbóreo & $\mathrm{CC}, \mathrm{M} 1$ & $\mathrm{~S}$ & 16797 \\
\hline Xylosma ciliatifolium (Clos.) Eichler & $\begin{array}{l}\text { espinho-de-judeu; espinho- } \\
\text { bravo; espinho-de-roseta }\end{array}$ & Arbóreo & $\mathrm{CC}$ & - & 16799 \\
\hline \multicolumn{6}{|l|}{ LAMIACEAE } \\
\hline Hyptis carpinifolia Benth. & rasmaninho & Herbáceo & I & $\mathrm{S}$ & 16800 \\
\hline Peltodon radicans Pohl. & hortelã-do-mato (verdadeiro) & Herbáceo & M1 & $\mathrm{S}$ & 16802 \\
\hline Peltodon sp. & hortelã-do-mato & Herbáceo & M1 & $\mathrm{S}$ & 16801 \\
\hline \multicolumn{6}{|l|}{ LAURACEAE } \\
\hline Nectandra lanceolata Nees & canela-branca & Arbóreo & M3 e CC & - & 16807 \\
\hline N. megapotamica (Sprengel) Mez & $\begin{array}{l}\text { canela-batalha; } \\
\text { canelinha-branca }\end{array}$ & Arbóreo & M3 e CC & - & 16808 \\
\hline N. oppositifolia Nees & canela-amarela & Arbóreo & M3 e CC & - & \\
\hline Ocotea odorifera (Vell.) Rohwer & sassafrás & Arbóreo & $\mathrm{L} ; \mathrm{RP} ; \mathrm{M} 3$ e CC & S & \\
\hline O. velloziana Meisner & canela-preta & Arbóreo & $\mathrm{M} 3$ e $\mathrm{CC}$ & - & 16812 \\
\hline Persea pyrifolia Nees & massaranduba & Arbóreo & M3 & - & 16813 \\
\hline \multicolumn{6}{|l|}{ LOGANIACEAE } \\
\hline $\begin{array}{l}\text { Strychnos brasiliensis (Sprengel) Mart. } \\
\text { LYTHRACEAE }\end{array}$ & \multicolumn{4}{|c|}{ LYTHRACEAE } & 16839 \\
\hline Lafoensia pacari A. St.-Hil. & dedal & Arbóreo & $\mathrm{CC}$ & - & 16850 \\
\hline \multicolumn{6}{|l|}{ MAGNOLIACEAE } \\
\hline Talauma ovata A. St.-Hil. & pinho-do-brejo & Arbóreo & $\mathrm{CC}, \mathrm{CO}$ & - & 16842 \\
\hline \multicolumn{6}{|l|}{ MALVACEAE } \\
\hline Ceiba speciosa (A. St.-Hil.) Gibbs \& Semir & paineira & Arbóreo & $\mathrm{AL} ; \mathrm{T}$ & - & 16754 \\
\hline Luehea divaricata Mart & $\begin{array}{l}\text { açoita-cavalo; salta-cavalo; } \\
\text { tramanca }\end{array}$ & Arbóreo & $\mathrm{L} ; \mathrm{G}$ & $\mathrm{S}$ & 16854 \\
\hline \multicolumn{6}{|l|}{ MELASTOMATACEAE } \\
\hline Miconia pepericarpa DC. & santo-antônio & Arbóreo & $\mathrm{L} ; \mathrm{M} 2$ & $\mathrm{C}$ & 16841 \\
\hline Tibouchina stenocarpa (DC.) Cogn. & quaresma & Arbóreo & $\mathrm{Ol}, \mathrm{L}$ & $\mathrm{S}$ & 16859 \\
\hline \multicolumn{6}{|l|}{ MELIACEAE } \\
\hline Cabralea canjerana (Vell.) Mart. & canjerana & Arbóreo & CA & - & \\
\hline Cedrela fissilis Vell. & cedro & Arbóreo & $\mathrm{M} 1, \mathrm{G}$ & $\mathrm{S}$ & 16860 \\
\hline \multicolumn{6}{|l|}{ MORACEAE } \\
\hline Brosimum gaudichaudii Trécul & manacá & Arbustivo & M1 & $\mathrm{S}$ & 16866 \\
\hline Dorstenia brasiliensis Lam. & carapiá & Herbáceo & $\mathrm{M} 1, \mathrm{ACI}$ & $\mathrm{S}$ & 16867 \\
\hline Ficus mexiae Standl. & figueira & Arbóreo & $\mathrm{CC}$ & - & 16868 \\
\hline Maclura tinctoria D. Don. ex Steud. & moreira & Arbóreo & $\mathrm{L}, \mathrm{CC}$ & $\mathrm{S}$ & 16869 \\
\hline \multicolumn{6}{|l|}{ MYRSINACEAE } \\
\hline Myrsine guianensis (Aublet) Kuntze & $\begin{array}{l}\text { cotovelo; carvãozinho- } \\
\text { do-campo }\end{array}$ & Arbóreo & $\mathrm{CC}$ & - & \\
\hline M. lancifolia Mart. & pororoca-do-campo & Arbóreo & $\mathrm{CC}$ & - & 16872 \\
\hline M. umbellata Mart. & pororoca; capororoca & Arbóreo & $\mathrm{M} 1, \mathrm{~L}$ & $S$ & 16873 \\
\hline \multicolumn{6}{|l|}{ MYRTACEAE } \\
\hline Blepharocalyx salicifolius (Kunth) O. Berg & jambo-do-campo & Arbóreo & $\mathrm{CC}$ & - & 16874 \\
\hline Calyptranthes clusiifolia (Miq.) O. Berg & orelha-de-burro & Arbóreo & $\mathrm{CC}$ & - & 16876 \\
\hline Campomanesia guazumifolia (Cambess.) O. Berg & $\begin{array}{l}\text { sete-casacas; sete-casacas- } \\
\text { da-miúda }\end{array}$ & Arbóreo & $\mathrm{CF} ; \mathrm{L}$ & $\mathrm{S}$ & 16877 \\
\hline C. pubescens (DC.) O. Berg & gabiroba & Arbustivo & $\mathrm{AL} ; \mathrm{CC}$ & - & \\
\hline Eugenia neomyrtifolia Sobral & catiguá & Arbóreo & $\mathrm{CB}$ & - & 16881 \\
\hline E. uniflora $\mathrm{L}$. & pitanga & Arbóreo & $\mathrm{CF} ; \mathrm{L}$ & S & 16885 \\
\hline Myrcia multiflora (Lam.) DC. & cambuí & Arbóreo & $\mathrm{L}$ & $\mathrm{SeC}$ & 16890 \\
\hline M. rostrata $\mathrm{DC}$ & piúna & Arbóreo & $\mathrm{L}$ & $\mathrm{S}$ e $\mathrm{C}$ & 16891 \\
\hline Pimenta pseudocaryophyllus (Gomes) Landrum & carvão & Arbóreo & $\mathrm{CC}$ & - & 16895 \\
\hline Psidium guajava $\mathrm{L}$. & goiabeira & Arbóreo & $\mathrm{M} 1, \mathrm{~L}$ & $\mathrm{SeC}$ & 16897 \\
\hline
\end{tabular}


Tabela 1 (continuação)

\begin{tabular}{|c|c|c|c|c|c|}
\hline Família/Espécie & Nome vulgar & Hábito & Uso & Destino & $\begin{array}{l}\text { Registro } \\
\text { ESAL }\end{array}$ \\
\hline Psidium guianense $\mathrm{Sw}$. & araçá & Arbustivo & $\mathrm{L} ; \mathrm{AL}$ & S & \\
\hline P. rufum Mart. & $\begin{array}{l}\text { goiabeira-do-mato; gioabeira- } \\
\text { brava }\end{array}$ & Arbóreo & $\mathrm{L}$ & $\mathrm{S}$ e C & 16898 \\
\hline Siphoneugena widgreniana O. Berg & brasa-viva & Arbóreo & $\mathrm{L}$ & $\mathrm{S}$ e C & \\
\hline \multicolumn{6}{|l|}{ OXALIDACEAE } \\
\hline Oxalis hirsutissima Mart. \& Zucc. & azedinha & Herbáceo & M1 & $\mathrm{S}$ & 16902 \\
\hline \multicolumn{6}{|l|}{ PICRAMNIACEAE } \\
\hline \multicolumn{6}{|l|}{ POLYGALACEAE } \\
\hline $\begin{array}{l}\text { Bredemeyera laurifolia (St. A.-Hil. \& Mog) Kl. } \\
\text { PROTEACEAE }\end{array}$ & joão-da-costa & Herbáceo & M1 & $\mathrm{S}$ & 16905 \\
\hline Roupala montana Aublet & carne-de-vaca & Arbóreo & $\mathrm{CC}$ & - & 16908 \\
\hline \multicolumn{6}{|l|}{ ROSACEAE } \\
\hline Rubus urticaefolius Poir. & amorinha & Arbustivo & M1 & $S$ & 16955 \\
\hline \multicolumn{6}{|l|}{ RUBIACEAE } \\
\hline Alibertia concolor (Cham.) K. Schum. & marmelada & Arbóreo & $\mathrm{L}$ & $\mathrm{S}$ e C & 16911 \\
\hline Amaioua guianensis Aublet & marmelada & Arbóreo & & $\mathrm{S}$ e $\mathrm{C}$ & 16913 \\
\hline Guettarda viburnoides Cham. \& Schltdl. & canjica & Arbóreo & $\mathrm{CC}$ & - & 16915 \\
\hline Palicourea coriacea (Cham.) K. Schum. & $\begin{array}{l}\text { douradinha; congonha- } \\
\text { do-campo }\end{array}$ & Herbáceo & M1 & $\mathrm{S}$ & 16918 \\
\hline Psychotria sp. & $\begin{array}{l}\text { guiné; giné-pulga-preta; } \\
\text { guinezinho-do-campo }\end{array}$ & Herbáceo & M1 & $\mathrm{S}$ & 16956 \\
\hline Randia nitida (Kunth) DC. & limãozinho-do-mato & Arbóreo & $\mathrm{CB}$ & - & 16920 \\
\hline Relbunium hirtum Schum. & tomba-carro & Herbáceo & $\mathrm{V}$ & $\mathrm{S}$ & 16930 \\
\hline Rudgea viburnoides (Cham.) Benth. & congonha-do-bugre & Arbóreo & M1 & $\mathrm{S}$ & 16921 \\
\hline Spermacoce cf. tenella H.B.K & cordão-de-frade & Herbáceo & M1 & $\mathrm{S}$ & 16957 \\
\hline \multicolumn{6}{|l|}{ RUTACEAE } \\
\hline Galipea jasminiflora (A. St.-Hil) Engler & canela-de-viado & Arbóreo & $\mathrm{CC}$ & - & 16922 \\
\hline Zanthoxylum rhoifolium Lam. & mamica-de-porca & Arbóreo & $\mathrm{L}$ & $\mathrm{S}$ & 16924 \\
\hline \multicolumn{6}{|l|}{ SAPINDACEAE } \\
\hline Cupania vernalis Cambess. & camboatá & Arbóreo & $\mathrm{M} 1, \mathrm{CC}$ & $S$ & 16925 \\
\hline \multicolumn{6}{|l|}{ SCROPHULARIACEAE } \\
\hline Scoparia dulcis $\mathrm{L}$. & vassourinha-doce & Herbáceo & M1 & $\mathrm{S}$ & 16928 \\
\hline \multicolumn{6}{|l|}{ SMILACACEAE } \\
\hline Smilax cissoides Mart. & japecanga-do-cupim & Trepadeira & M1 & $\mathrm{S}$ & 16929 \\
\hline \multicolumn{6}{|l|}{ SOLANACEAE } \\
\hline Datura stramonium L. & mata-carneiro & Herbáceo & M1 & $\mathrm{S}$ & 16932 \\
\hline Solanum lycocarpum A. St.-Hil & lobeira & Arbustivo & M1 & $\mathrm{S}$ & 16933 \\
\hline S. paniculatum L. & jurubeba & Arbóreo & M1 & $\mathrm{S}$ & 16935 \\
\hline S. subumbellatum Vell. & velame-do-cupim & Herbáceo & M1 & $\mathrm{S}$ & 16934 \\
\hline \multicolumn{6}{|l|}{ STYRACACEAE } \\
\hline Styrax camporum Pohl & cotovelo & Arbóreo & $\mathrm{CC}$ & - & 16936 \\
\hline \multicolumn{6}{|l|}{ THYMELAEACEAE } \\
\hline Daphnopsis brasiliensis Mart. \& Zucc. & imbira-branca & Arbóreo & $\mathrm{L}, \mathrm{AM}$ & $\mathrm{C}$ & 16938 \\
\hline D. fasciculata (Meisner) Nevl. & imbira-vermelha & Arbóreo & $\mathrm{L}, \mathrm{AM}$ & $\mathrm{C}$ & 16939 \\
\hline \multicolumn{6}{|l|}{ VERBENACEAE } \\
\hline Lantana camara $\mathrm{L}$. & cambarazinho & Arbustivo & M1 & $\mathrm{S}$ & 16948 \\
\hline \multicolumn{6}{|l|}{ VOCHYSIACEAE } \\
\hline Callisthene major Mart. & aroeirinha & Arbóreo & $\mathrm{CC}$ & - & 16947 \\
\hline Qualea sp. & dedal (dedalo) & Arbóreo & $\mathrm{CC}, \mathrm{L}$ e $\mathrm{M} 2$ & $\mathrm{~S}$ e $\mathrm{C}$ & 16950 \\
\hline Qualea multiflora Mart. & $\begin{array}{l}\text { boizinho-do-campo; } \\
\text { cavalinho-do-campo }\end{array}$ & Arbóreo & $\mathrm{L}$ & S & \\
\hline Vochysia thyrsoidea Pohl & congonha & Arbóreo & LM1 & SS & 16951 \\
\hline
\end{tabular}

Uso: M1 = Medicinal, M2 = Moirão, M3 = Móveis, $\mathrm{L}=$ Lenha, $\mathrm{AL}=$ Alimentação, $\mathrm{CB}=$ Carro de boi, $\mathrm{I}=$ Incenso, $\mathrm{R}=\mathrm{Rolhas}, \mathrm{O}=\mathrm{Ornamental}$, $\mathrm{G}=$ Gamela, $\mathrm{CO}=$ Colher, $\mathrm{T}=$ Travesseiro, $\mathrm{CA}=$ Canoas, $\mathrm{V}=$ Vassoura, $\mathrm{RP}=$ Rapé, $\mathrm{AM}=$ Amarração, $\mathrm{CCO}=\mathrm{Curtir}$ couro, $\mathrm{RC}=\mathrm{Régua}$ de curral, $\mathrm{APP}=$ Alimento para pássaros, $\mathrm{CC}=$ Construção de casas, $\mathrm{AP}=$ Arco de peneira, $\mathrm{CF}=$ Cabo de ferramenta, $\mathrm{ACI}=\mathrm{Aromatizar}$ cigarros, $\mathrm{FM}=$ Ferramenta de marcenaria; Destino: $\mathrm{S}=$ Subsistência, $\mathrm{C}=$ Comercialização. 
trimera (Less.) DC., Mikania hirsutissima D.C., Mikania sessilifolia D.C., Vernonia polyanthes Less), duas para feitio de moirões (Eremanthus erythropappus (DC.) MacLeish, Eremanthus incanus (Less.) Less.) e as restantes, junto com Vernonia polyanthes Less, para lenha.

De acordo com as informações da população local, as categorias de usos da vegetação foram divididas em quatro tipos:

1. madeira: espécies usadas para construção civil e fabricação de móveis;

2. medicinal: espécies apontadas como tendo algum uso terapêutico;

3. lenha: espécies usadas como combustível;

4. diversos usos: espécies usadas na fabricação de artesanato, ferramentas, carros de boi e utilizadas na alimentação.

Das plantas citadas $56(39,16 \%)$ foram indicadas como úteis para fins madeireiros $53(37,06 \%)$ como medicinais e $37(25,87 \%)$ na categoria lenha (ruim ou boa). Para a categoria diversos usos, foram citadas 32 espécies $(22,37 \%)$. Muitas espécies foram mencionadas para dois ou mais usos, como por exemplo, Talauma ovata A. St.-Hil. (construção civil e feitio de colheres), Actinostemon concolor (Sprengel) Müll. Arg. (carro de boi, ferramenta para marcenaria, lenha e construção civil), Bowdichia virgilioides Kunth (medicinal, construção civil e fabricação de móveis) e Machaerium hirtum (Vell.) Stellfeld (lenha, construção civil e fabricação de móveis),

O índice de diversidade de Shannon para uso das espécies foi de $H^{\prime}=4,84$. Esse valor pode ser considerado alto quando comparado com os resultados do trabalho de Begossi (1996), que apresentou índices de diversidade para vários países variando entre 2,99 (Nicarágua) e 5,95 (México). Para essa autora, índices de diversidade altos sugerem que a população utiliza uma grande parcela da diversidade local e espera-se que quanto maior a diversidade florística local, maior a diversidade de espécies usadas.

O levantamento florístico e estrutural da Mata da Ilha mostrou que tanto o índice de diversidade $\left(H^{\prime}=3,73\right)$ quanto o de equabilidade $\left(\mathrm{J}^{\prime}=0,76\right)$ foram baixos, se comparados a outras comunidades vegetais da região, indicando forte dominância ecológica nesse remanescente. Como esse estudo só inclui espécies com $\mathrm{DAP} \geq 15,5 \mathrm{~cm}$, estimamos também a diversidade de uso apenas das espécies arbustivas e arbóreos do levantamento etnobotânico (correspondendo a 80,5\% do total de plantas citadas). Ao contrário da baixa diversidade de espécies encontrado para a Mata da Ilha, a diversidade de usos de espécies arbustivas e arbóreos foi alta $\left(\mathrm{H}^{\prime}=4,7\right)$. Esse resultado mostra que a população estudada conhece e utiliza a maior parte das espécies disponíveis no ambiente e que não há um predomínio no uso de apenas algumas espécies, o que é confirmado também pelo alto valor de equabilidade, tanto para o uso da flora em geral $\left(\mathrm{J}^{\prime}=0,95\right)$ quanto para o uso apenas de espécies arbustivas e arbóreos $\left(\mathrm{J}^{\prime}=0,95\right)$.

Os altos valores para os índices de diversidade de usos foram, em parte, devido ao grande número de espécies citadas que, por sua vez, pode ter sido influenciado pela idade dos informantes e pelo contato que estes tiveram ou ainda têm com a área rural. Um exemplo disso é o caso do informante sete (54 anos), que viveu durante 28 anos na zona rural, tendo contato regular com essa região e que, sozinho, citou 130 espécies de vários hábitos e usos.

Ao comparar os índices de diversidade da flora e de diversidade de usos deve-se considerar que os procedimentos para a obtenção de ambos são diferentes. Enquanto para o primeiro há uma separação entre o pesquisador e o fato observado e é possível a quantificação de todos os resultados obtidos, para o segundo, não se tem controle sobre as variáveis, pois as informações usadas para o cálculo estão sujeitas à memória de quem dá a informação, ao contexto histórico do local em que o informante vive e à própria interpretação do pesquisador na coleta dos dados.

$\mathrm{O}$ contato dessas pessoas com o ambiente se refletiu, também, na forma como elas diferenciaram tipos de vegetação. As áreas "com mais árvores juntas", foram denominadas pelos informantes como mato. Como campo foram chamados os locais com vegetação rasteira e cerrado aqueles com poucas árvores esparsas. $\mathrm{O}$ termo terreno de cultura foi muito usado para designar os locais arados que já foram ou ainda são usados para plantios agrícolas.

Durante as entrevistas notou-se ainda uma certa preferência por tipos fisionômicos e plantas de determinados locais: "cerrado é mato ruim. A gente planta e não dá mantimento"; "madeira boa é que dá no mato, a do cerrado não é boa". Isso pode ser devido ao fato de as áreas mais férteis estarem geralmente localizadas próximas aos cursos d'água onde naturalmente ocorrem as matas ciliares. Segundo Resende et al. (1988), é comum que a fertilidade química dos solos de uma catena cresça do topo para a base da encosta. Como exemplo podemos citar o estudo da Mata da Ilha em que os solos que estão sob 
influência direta do curso d'água apresentaram fertilidade química mais elevada e drenagem mais restrita, onde ocorre a floresta estacional semidecidual aluvial, enquanto aqueles mais distantes foram os mais pobres em nutriente e melhor drenados, onde podemos encontrar espécies de cerradão.

Outro fato importante é que a proteção contra o fogo que algumas árvores do cerrado possuem, representada pela cortiça, e seu aspecto retorcido faz com que as pessoas as classifiquem como uma "madeira à toa", ou seja, adequada somente para feitio de rolhas. No entanto, apesar das espécies de cerrado serem consideradas como madeiras ruins, foram as mais citadas como medicinais, indicando o grande potencial terapêutico existente nessas áreas, como já foi mostrado por Rodrigues e Carvalho (2001).

A forma de identificação das plantas variou de acordo com a experiência de cada informante. $\mathrm{O}$ informante 1, por exemplo, que demonstrou um grande conhecimento da vegetação, reconhecia as plantas de acordo com seu estádio evolutivo: as plantas jovens eram identificadas pelas folhas e as adultas pela casca. Para plantas muito semelhantes ou aquelas pertencentes a um mesmo gênero, outras características de identificação foram utilizadas, como é o exemplo de Nectandra megapotamica (Sprengel) Mez (canela-batalha), que segundo o informante "diferencia das outras canelas pela cor e pelos veios da casca".

Assim como no saber científico, os informantes dividem as espécies em famílias de acordo com características comuns que estas apresentam: "canjerana é da mesma família do cedro", "paineira é da mesma família do quiabo". Este último comentário se deve ao fato de as folhas mais novas da paineira serem usadas como alimento e seu sabor se assemelhar ao do quiabo.

A classificação das espécies em famílias indica o alto grau de observação de um homem simples com respeito à vegetação, pois somente no novo sistema de classificação (Angyosperm Phylogeny Group 1998), realizado com o auxílio de testes de DNA, Ceiba speciosa (A. St.-Hil.) Gibbs \& Semir (paineira), que pertencia à família Bombacaceae nos sistemas de classificação tradicionais, passou a integrar a família do quiabo (Hibiscus esculentus L. família Malvaceae).

O exemplo citado acima é ilustrativo do que Thiollent (2002) chamou de saber especialista, definido por ele como aquele dotado de capacidade de abstração, e saber informal, que é resultado da experiência concreta das pessoas comuns. Esse autor adverte que, embora alguns pesquisadores acreditem que os membros das classes populares não sabem nada, não conseguem dominar raciocínios abstratos e que os especialistas nunca erram, geralmente o saber popular é rico e espontâneo. Para ele, o saber do especialista deveria estabelecer formas de comunicação e de intercompreensão com os agentes do saber popular.

Com relação aos nomes vulgares, algumas vezes o mesmo nome foi dado a espécies diferentes por um mesmo informante. Isso se deve ao fato de algumas espécies serem morfologicamente muito semelhantes, como no caso de Davilla rugosa Poir. e Doliocarpus dentatus (Aubl.) Standl., ambas vulgarmente chamadas de cipó-caboclo. O contrário também pode ocorrer quando uma mesma espécie apresenta variações morfológicas de acordo com o ambiente. Como exemplo podemos citar espécies que apresentam folhas maiores em locais com menos luz e menores a pleno sol; ou texturas de folhas diferentes como encontradas para Casearia sylvestris Swartz, que apresenta variações morfológicas entre os espécimes que ocorrem em áreas de cerrado daqueles encontrados em áreas de matas.

As espécies mais citadas como tendo efeito terapêutico foram Bredemeyera laurifolia (A. St.-Hil. \& Mog) Kl, Ilex cerasifolia Reisseck, Psychotria sp., Solanum lycocarpum A. St.-Hil. e Stryphnodendron adstringens (Mart.) Cov. (Tab. 2). Com relação à concordância quanto ao uso principal (CUP), apenas B. laurifólia (A. St.-Hil. \& Mog) Kl, apresentou valor abaixo de $60 \%$. As espécies Brosimum gaudichaudii Trécul, Cybistax antisyphillitica Mart., Erythrina falcata Benth., Dorstenia brasiliensis Lam., Echinodorus grandiflorus Mitch, I. cerasifolia Reisseck, S. lycocarpum A. St.-Hil., Smilax cissoides Mart. e Strychnos brasiliensis (Sprengel) Mart. apresentaram CUP igual a $100 \%$.

A concordância quanto ao uso principal em relação à espécie mais citada (CUPc) apresentou valores variando entre $33,3 \%$ e $100 \%$. Apenas Vernonia polyanthes e Croton antisyphiliticus apresentaram valores inferiores a $40 \%$. As outras espécies tiveram valores superiores a $60 \%$, merecendo destaque Ilex cerasifolia Reisseck e Solanum lycocarpum A. St.-Hil., com valores integrais de CUPc.

Altos valores de CUP e CUPc, podem fornecer a base para estudos mais aprofundados das espécies com potencial de uso terapêutico para certas doenças (Amorozo \& Gély 1988). Ilex cerasifolia Reisseck, 
Tabela 2. Importância relativa das espécies medicinais citadas por três ou mais informantes no município de Ingaí, MG, Brasil, de acordo com seu uso principal e concordância quanto ao uso principal. CUP = Percentagem de concordância quanto aos usos principais; $\mathrm{FC}=$ Fator de correção; $\mathrm{CUPc}=$ Percentagem de concordância quanto aos usos principais corrigida.

\begin{tabular}{|c|c|c|c|c|c|c|c|}
\hline Espécie & nformantes & $\begin{array}{l}\text { Número } \\
\text { de usos }\end{array}$ & Usos principais & $\begin{array}{l}\text { Citação do } \\
\text { uso principal }\end{array}$ & CUP & $\mathrm{FC}$ & CUPc \\
\hline $\begin{array}{l}\text { Bredemeyera laurifolia (A. St.- Hil. \& } \\
\text { Mog) Kl. }\end{array}$ & 6 & 3 & $\begin{array}{l}\text { infecção de útero e ovários, } \\
\text { engravidar }\end{array}$ & 3 & 50,0 & 1,0 & 50,0 \\
\hline Ilex cerasifolia Reisseck & 6 & 7 & infecção de rins & 6 & 100,0 & 1,0 & 100,0 \\
\hline Psychotria sp. & 6 & 4 & dores no corpo e dor de dente & 4 & 66,7 & 1,0 & 66,7 \\
\hline Solanum lycocarpum A. St.-Hil. & 6 & 1 & depurativo do sangue & 6 & 100,0 & 1,0 & 100,0 \\
\hline Stryphnodendron adstringens (Mart.) Cov. & 6 & 3 & cicatrizante & 4 & 66,7 & 1,0 & 66,7 \\
\hline Baccharis trimera (Less.) DC. & 5 & 4 & males do estômago & 4 & 80,0 & 0,8 & 66,7 \\
\hline Brosimum gaudichaudii Trécul & 4 & 1 & depurativo do sangue & 4 & 100,0 & 0,7 & 66,7 \\
\hline Cybistax antisyphillitica Mart. & 4 & 2 & depurativo do sangue & 4 & 100,0 & 0,7 & 66,7 \\
\hline Erythrina falcata Benth. & 4 & 1 & depurativo do sangue & 4 & 100,0 & 0,7 & 66,7 \\
\hline Jacaranda decurrens Cham. & 4 & 2 & depurativo do sangue & 3 & 75,0 & 0,7 & 50,0 \\
\hline Palicourea coriacea (Cham.) K. Schum. & 4 & 2 & infecção de rins & 3 & 75,0 & 0,7 & 50,0 \\
\hline Croton antisyphiliticus Muell. Arg. & 3 & 2 & infecção de útero e ovários & 2 & 66,7 & 0,5 & 33,3 \\
\hline Dorstenia brasiliensis Lam. & 3 & 2 & tosse; dor de dente & 3 & 100,0 & 0,5 & 50,0 \\
\hline Smilax cissoides Mart. & 3 & 1 & depurativo do sangue & 3 & 100,0 & 0,5 & 50,0 \\
\hline Strychnos brasiliensis (Sprengel) Mart. & 3 & 2 & males do estômago & 3 & 100,0 & 0,5 & 50,0 \\
\hline Vernonia polyanthes Less & 3 & 3 & pneumonia & 2 & 66,7 & 0,5 & 33,3 \\
\hline
\end{tabular}

por exemplo, citada para infecção de rins, diurético e calmante, com valores de CUP e CUPc iguais a 100\%, merece atenção especial. Espécies pertencentes a esse gênero, tal como I. paraguariensis (erva-mate), possuem comprovado valor terapêutico devido à presença em sua composição química, de cafeína, teobromina, flavonóides e vitaminas que atuam no sistema cardiovascular e respiratório, tecido muscular, trato intestinal e sistema nervoso central, além de ser considerada como diurética (Valduga et al. 2000).

Entre os fatores que podem influenciar na opção pelo uso de plantas como terapêuticas pode ser o econômico e a pouca estrutura que o município possui para tratar os seus enfermos, sendo necessário se deslocarem até o município de Lavras, a $30 \mathrm{~km}$ de distância.

O fator econômico pode estar relacionado também ao uso da lenha como combustível. Mais de dois terços da humanidade usa a lenha para cocção de alimento e às vezes para aquecimento (Flores-Lopes, dados não publicados). Na sede do município de Ingaí, MG, o uso da lenha pela maioria das famílias é muito comum. Não raro, pode-se observar durante caminhadas pela cidade, a presença de chaminés, serpentinas e feixes de lenha armazenados nas residências. Dos 17 entrevistados, somente um não possuía fogão à lenha devido a problemas respiratórios.

A existência da comercialização de lenha de espécies nativas no município foi citada por mais de um informante. No entanto, a maioria das pessoas preferiu não falar no assunto por medo da fiscalização por parte de órgãos ambientais, fazendo apenas alguns comentários: "lenha agora é só de eucalipto... antes era óleo-copaiba, goiabeira-do-mato, capororoca"; madeira de cerrado não acha, só acha de eucalipto, por causa do IBAMA."

De acordo com o informante 12, a carga de uma charrete vendida regularmente no município custa $\mathrm{R} \$ 15,00$ (dado do ano de 2000) e é suficiente para um mês de consumo. A prática da compra de lenha geralmente ocorre durante a época chuvosa e durante a colheita de café, quando as coletoras de lenha possuem menor disponibilidade para coletar seu próprio combustível, por estarem trabalhando na colheita. Geralmente as coletoras de lenha mais experientes evitam buscá-la imediatamente após períodos chuvosos, alegando que estas se tornam extremamente pesadas.

Nas outras estações do ano, a maioria das mulheres coletoras busca lenha todos os dias, exceto o informante 12, que prefere coletar de uma vez só o suficiente para o consumo no período de uma semana. A coleta, na maior parte das vezes, é realizada em grupo, com a participação de várias coletoras. Apenas uma informante preferia ir sozinha ou com os filhos. Feita em grupo, a coleta de lenha parece ser uma atividade prazerosa por se tornar um momento de confraternização entre elas. A atividade da coleta de 
lenha se caracteriza como um processo de integração intensa, desenvolvendo um sentimento coletivo de solidariedade social e cooperação entre os indivíduos associados em grupos. Durante os relatos, não foi registrada nenhuma queixa indicando insatisfação ao coletar lenha.

De acordo com os informantes, a maior parte dos proprietários rurais permite a retirada de lenha em suas propriedades, desde que seja somente feixes de galhos secos carregados na cabeça: Durante o acompanhamento a uma coleta de lenha foi detectada a presença de cepas com marcas de machado no interior do fragmento florestal, sem no entanto ser possível saber a qual uso se destinou esses espécimes.

Alguns proprietários proíbem a coleta de lenha em suas propriedades e por isso o informante 14, que também é um proprietário de terras no município, defende as coletoras de lenha. Segundo ele, essas proibições dificultam o trabalho das mulheres e que um outro problema que elas enfrentam é devido à polícia florestal dando a entender que antes a coleta de lenha era mais intensiva.

O uso de lenha que não seja de espécies nativas não é muito comum. No entanto, às vezes elas utilizam lenha proveniente de reflorestamento, e consideram que o eucalipto como de boa qualidade. A coleta é inclusive adaptada para essa espécie, usando ganchos para puxar os galhos. Uma outra alternativa à lenha de espécies nativas seria a lenha proveniente de cafezais. No entanto, opiniões com relação à sua qualidade não são unânimes. Apesar da ser considerada de boa qualidade por alguns, foi considerada ruim pelas mulheres entrevistadas, persistindo, entre elas, a preferência por nativas.

Quando questionadas a respeito da escassez de lenha, algumas coletoras afirmaram que "antes tinha muita lenha, agora tem que andar muito pra buscar". Isso mostra que as coletoras percebem as transformações que ocorrem na paisagem como resultado do processo de ocupação dos espaços.

Durante uma coleta programada com uma das coletoras, foi realizada uma caminhada de 30 minutos até o local da coleta. Constatou-se que a facilidade de obter lenha com maior rapidez é um privilégio das coletoras mais jovens, visto que aquelas que citaram distâncias maiores para encontrar o combustível são mais velhas e muitas vezes já não praticam a atividade de coleta, geralmente por problemas de saúde. Algumas dessas coletoras inativas atualmente obtêm lenha por meio de terceiros. Somente uma delas substituiu totalmente o uso do fogão à lenha pelo fogão a gás, indicando que a tradição no uso da lenha pela população local continua.

A restrição ao uso de certas espécies, independente de serem boas ou ruins para uso lenheiro, também foi detectada. Espécies como Cedrela fissilis Vell. (cedro), destinada a usos nobres, e Eremanthus incanus (Less.) Less. (candeia), utilizada como mourão, geralmente são poupadas do uso como lenha.

Outra restrição ocorre com relação a espécies cujo uso provocariam problemas de saúde. Litrhaea molleoides (Vell.) Engler (aroeira), por exemplo, devido à alergia que causa quando viva, só é coletada seca. Além disso, essa espécie é considerada pesada e, por isso, de acordo com alguns informantes, muitas vezes é dispensada, já que geralmente quem faz a coleta de lenha são mulheres, que suportam menor peso que os homens. Já Lafoensia pacari A. St.-Hil. (dedal) é considerada venenosa e não é queimada porque " $a$ fumaça prejudica as vistas". Esses procedimentos talvez diminuam a pressão sobre essas espécie, pelo menos para uso como lenha..

Algumas espécies consideradas como de boa qualidade para uso como lenha são evitadas também devido a conotação sagrada ou mágicas atribuídas a elas, mostrando que a crença popular tem um papel importante no controle do uso de algumas espécies, como se percebe nos depoimentos abaixo:

"Óleo-copaíba é boa lenha, mas dizem que atrai trovão".

"Barbatimão eu não coletava pra lenha, pra não atrair trovão".

"Cedro não pode queimar porque a cruz de Jesus foi feita de cedro".

"Embaúba não pode queimar porque quando Nossa Senhora fugia com Jesus, a embaúba abriu e Ela escondeu O filho lá dentro".

"Santo-antônio é lenha ruim e dá azar queimar. Ele chora roxo e espirra igual foguete".

"Embaúba é lenha ruim e os antigos falavam que não pode queimar, dá azar e chora no olho".

As interpretações que uma sociedade faz dos acontecimentos e as explicações que produzem expressam o saber popular. A explicação mágica atribuída a alguns fenômenos não são simplesmente fatos imaginários e sim, resultado do que essa sociedade institucionaliza como real (Martinic 1994).

O conhecimento sobre vegetação no município de Ingaí, de acordo com a maioria dos entrevistados, foi passado de geração para geração, e nesta pesquisa não foi detectada nenhuma forma de influência vinda de meios de comunicação, como rádio e televisão. 
Porém, durante as entrevistas foi relatada a existência de um raizeiro, hoje já falecido, que curava as pessoas que o procuravam por meio do conhecimento adquirido na literatura.

Somente cinco dos entrevistados disseram que costumam passar o conhecimento que adquiriram dos pais para outras pessoas, o que pode levar a uma perda desse conhecimento caso não haja interesse, principalmente por parte dos jovens, em procurar por esse tipo de informação.

Esse conhecimento é resultado de anos de experimentação daqueles que usam a vegetação e possibilita a escolha da espécie de acordo com o uso a que se destina, como por exemplo, na construção de carros de boi e no feitio de gamelas. Para cada peça que compõe o carro de boi é usada uma espécie adequada. Para a confecção da cheda (mesa do carro de boi) é utilizado Platyciamus regnellii Benth. (pereira); para a tiradeira (uma das peças utilizada para atrelar os bois ao carro), Actinostemon concolor (Sprengel) Müll. Arg. (batinga); para as rodas, Bowdichia virgilioides Kunth (sucupira); e para o freiro (cerca colocada ao redor da mesa do carro de boi para transporte da carga) Eugenia neomyrtifolia Sobral (catiguá). Para o feitio de gamelas (utensílio doméstico semelhante a uma tigela) as espécies escolhidas não devem ter "gosto ruim". Lafoensia pacari A. St.-Hil. (dedal) deve ser evitado para este uso por ser considerada venenosa.

O informante seis é um dos marceneiros mais antigos do município de Ingaí e, antes de se aposentar, vivia basicamente da venda de gamelas e pequenos objetos que fazia em sua marcenaria. Ele conta que o interesse em aprender a arte da marcenaria por parte das crianças que vivem nas vizinhanças é muito grande. Estas crianças, inclusive, trazem pequenas partes de madeira encontradas em suas caminhadas pela vegetação para feitio de pequenas peças na marcenaria. Luehea divaricata Mart. \& Zucc. (açoita-cavalo) e Cedrela fissilis Vell. (cedro) são as preferidas para esse uso. A fabricação de ferramentas, usadas em marcenaria, com espécies madeireiras da região, também é um exemplo da versatilidade de usos dados à vegetação local.

Dentre outros usos encontrados pode-se citar ainda Daphnopsis sp. (embira), utilizada pelas coletoras de lenha nos locais de coleta para a amarração dos feixes de lenha, e as vassouras feitas utilizando Relbunium hirtum Schum. (tomba-carro) e Baccharis dracunculifolia DC. (alecrim-do-campo), de uso muito comum localmente.
Em princípio, o uso de alternativas para alguns produtos industrializados poderia ser simplesmente devido a fatores econômicos. Porém, com o tempo, os usuários aperfeiçoaram os utensílios que na maior parte das vezes são considerados melhores que aqueles "comprados na loja". Este é o caso dos travesseiros feitos com Ceiba speciosa (A. St.-Hil.) Gibbs \& Semir (paineira), que são bastante usados no município.

Quanto ao uso para alimentação, foi citado que as folhas jovens da Ceiba speciosa (A. St.-Hil.) Gibbs $\&$ Semir (paineira) e os frutos do Inga vera Willd. (ingá) são comestíveis.

A fragmentação a que vem sendo exposta a vegetação da região é um fato muito comentado pelos entrevistados: "essa mata já foi maior", "conheci uma fazenda que tinha muito pau, hoje o povo estragou demais". Quando questionados a esse respeito, tecem sua preocupação com relação aos desmatamentos: "a lei que entrou devia ter vigorado a mais tempo". Apesar desta preocupação, o corte seletivo de espécies arbóreos é uma realidade, constatada durante a coleta de material botânico, dentro de várias matas da região.

A relação estabelecida entre a vegetação e a população em Ingaí, MG, pode ser considerada estreita no que diz respeito à comercialização de produtos de origem vegetal, sendo, em alguns casos, a base da economia familiar, como ocorre com o informante 1 , que vive do comércio de balaios ou cestos de bambu. A comercialização de embira (Daphnopsis sp. e Lonchocarpus cultratus) para amarração, da candeia para mourões (Eremanthus sp.) e diversas espécies destinadas à lenha também foi mencionada.

Cada mourão de candeia (Eremanthus sp.) é vendido a R\$2,06 (dados do ano de 2000) e não há evidências da exploração dessa espécie para outros fins além deste, indicando o desconhecimento, por parte da população, em relação à importância farmacêutica e cosmética dessa espécie. Devido à presença, em seu óleo, da substância alfa-bisabolol, que possui uma potente ação antiinflamatória, esta tem sido largamente empregada pela indústria nacional e internacional (Paula 1997).

Entre os entrevistados foi possível verificar que o conhecimento em relação aos usos modifica-se com o gênero. Os homens citaram um maior número de espécies madeireiras, enquanto as mulheres se mostraram grandes conhecedoras de espécies com potencial lenheiro. Isto ocorreu devido às mulheres serem, na localidade, responsáveis pelo abastecimento de combustível de suas residências. De acordo com 
Shiva e Dankelman (1994), a especificidade de interesses entre homens e mulheres leva a uma diferenciação de suas percepções ambientais.

Apesar da importância econômica que algumas espécies têm para as famílias, não foi observada a preocupação em manejar tais recursos naturais. Este quadro poderia ser revertido, caso essa população viesse a se sensibilizar do papel fundamental que possui na conservação do ambiente em que vive.

Com os resultados desta pesquisa foi elaborado e distribuído um boletim técnico às lideranças locais e escolas do município. Sugere-se a realização de ações educativas (ensino formal e não formal) para que o conhecimento local não desapareça. Por parte das políticas públicas, espera-se que estratégias para a conservação das espécies sejam implementadas, e acredita-se que extensão rural poderia ser uma boa via.

Pode-se concluir com os resultados obtidos que a população pesquisada no município de Ingaí detém um grande conhecimento quanto às espécies nativas distribuídas nos vários estratos da vegetação e suas várias categorias de uso. A comercialização de espécies destinadas a uso lenheiro e feitio de mourões é uma atividade comercial comum no município. Já o uso de espécies medicinais e outros usos tem fins de subsistência.

\section{Agradecimentos}

Os autores agradecem aos docentes Ary Teixeira de Oliveira Filho e Valéria Evangelista Gomes, pela identificação do material botânico; aos alunos do Departamento de Engenharia Florestal da Universidade Federal de Lavras; ao funcionário José Carlos; à estagiária Érica Aparecida da Silva; ao PROBIO, pelo apoio financeiro; e, em especial, aos moradores do município de Ingaí, MG, pela colaboração durante a realização da pesquisa.

\section{Referências bibliográficas}

Alencar, E. \& Gomes, M.A.O. 1998. Metodologia de pesquisa social e diagnóstico rápido participativo. Lavras, UFLA/ FAEPE.

Amorozo, M.C.M. \& Gély, A. 1988. Uso de plantas medicinais por caboclos do baixo Amazonas. Barcarena, PA, Brasil. Boletim do Museu Paraense Emílio Goeldi, Série botanica 1(4): 47-131.

Angiospem Phylogeny Group (APG). 1998. An ordinal classification for the families of flowering plants. Annals of the Missouri Botanical Garden 4(85): 531-553.
Begossi, A. 1996. Use for ecological methods in ethnobotany: diversity indices. Economic Botany 3(50): 280-289.

Botrel, R.T.; Oliveira Filho, A.T.; Rodrigues, L.A. \& Curi, N. 2002. Influência do solo e topografia sobre as variações da composição florística e estrutura da comunidade arbóreo-arbustiva de uma floresta estacional semidecidual em Ingaí, MG. Revista Brasileira de Botânica 25: 195-213

Eidt, R.C. 1968. The climatology of south America. Pp. 54-81. In: E.J. Fittkau; J. Illies; H. Klinge; G.H. Schwabe \& J.C.H. Sioli (eds.). Biogeography and Ecology in South America. The Hague, Netherlands, Dr. W. Junk N.V. Publishers.

Fundação João Pinheiro, 1988 (on line). Disponível em <http://www.geominas.mg.gov.br>. Acesso em 20 de outubro de 2000.

Martinic, S. 1994. Saber popular e identidade. In: M. Gadotti \& C.A. Torres (orgs.). Educação popular: utopia LatinoAmericana. São Paulo, Cortez e EDUSP.

Nunes, Y.R.F.; Mendonça, A.V.R.; Botezelli, L.; Machado, E.L.M. \& Oliveira Filho, A.T. 2003. Variações da fisionomia, diversidade e composição de guildas da comunidade arbóreo em um fragmento de floresta semidecidual em Lavras, MG. Acta Botanica Brasilica 17: 213-229.

Oliveira Filho, A.T. \& Fluminhan Filho, M. 1999. Ecologia da vegetação do Parque Florestal Quedas do Rio Bonito. Cerne 5(2): 51-64. 12: 71-84.

Oliveira Filho, A.T. \& Machado, J.N.M. 1993. Composição florística de uma floresta semidecídua Montana na Serra de São José, Tiradentes, Minas Gerais. Acta Botanica Brasilica 7: 71-88.

Oliveira Filho, A.T.; Mello, J.M. \& Scolforo, J.R.S. 1997. Effects of past disturbance and edges on tree community structure and dynamics within a fragment of tropical semideciduous forest in Southeastern Brazil over a fiveyear period (1987-1992). Plant Ecology 131(1): 45-66.

Oliveira Filho, A.T.; Almeida, R.J.; Mello, J.M. \& Gavilanes, M.L. 1994a. Estrutura fitossociológica e variáveis ambientais em um trecho de mata ciliar do córrego Vilas Boas, Reserva Biológica do Poço Bonito, Lavras (MG). Revista Brasileira de Botânica 17(1): 67-85.

Oliveira Filho, A.T.; Scolforo, J.R. \& Mello, J.M. 1994b. Composição florística e estrutura comunitária de um remanescente de floresta semidecídua montana em Lavras, MG. Revista Brasileira de Botânica 17(2): 167-182.

Oliveira Filho, A.T.; Vilela, E.A.; Gavilanes, M.L. \& Carvalho, D.A. 1994e. Comparison of the woody flora and soils of six areas of montane semideciduous forest in southern Minas Gerais, Brazil. Edinburgh Journal of Botany 51(3): 355-389.

Paula, J.A. 1997. (coord.). Biodiversidade: população e economia. Belo Horizonte, Universidade Federal de Minas Gerais

Queiroz, R.; Souza, A.G; Santana, P.; Antunes, F.Z. \& Fontes, M. 1980. Zoneamento Agroclimático de Estado de Minas Gerais. Belo Horizonte, Secretraria da Agricultura. 
Resende, M.; Curi, N. \& Santana, D.P. 1988. Pedologia e fertilidade do solo: interações e interpretações. Brasília, DF, Ministério da Agricultura. Lavras, UFLA/FAEPE.

Rodrigues, V.E.G. \& Carvalho, D.A. 2001. Levantamento etnobotânico de plantas medicinais no domínio do cerrado na região do Alto Rio Grande - Minas Gerais. Revista Ciência e Agrotecnologia 25: 102-123.

Shiva, V. \& Dankelman, I. 1994. As mulheres e a diversidade biológica: lições do Himalaia indiano. In: A. Gaifami \& A. Cordeiro (orgs.). Cultivando a diversidade: recursos genéticos e segurança alimentar local. Rio de Janeiro.

Thiollent, M. 2002. Metodologia da pesquisa-ação. 11 ed. São Paulo, Cortez/Autores Associados.

Triviños, A.N.S. 1987. Introdução à pesquisa em ciências sociais: a pesquisa qualitativa em educação. São Paulo, Atlas.
Souza, J.S.; Espírito-Santo, F. Del Bon; Fontes, M.A.L.; Oliveira Filho, A.T. \& Botezelli, L. 2003. Análise das variações florísticas e estruturais da comunidade arbóreo de um fragmento de floresta semidecídua às margens do Rio Capivari, Lavras-MG. Revista Árvore 27: 185-206.

Valduga, A.T.; Battestin, V.; Finzer, J.R.D.; Cavalheiro, F. \& Cichoski, A. 2000. Utilização de liofilizado de extrato de erva-mate na fabricação de balas. Pp. 362-365. In: Anais do Congresso Sul-Americano de Erva-Mate e III Reunido Técnica de Cone Sul Sobre a Cultura da ErvaMate, 2. Encantado, Rio Grande do Sul. Porto Alegre, Ed. dos organizadores.

Vilela, E.A.; Oliveira Filho, A.T.; Carvalho, D.A.; Guilherme, F.A.G. \& Appolinário, V. 2000. Caracterização estrutural de floresta ripária do Alto Rio Grande, em Madre de Deus de Minas, MG. Cerne 6: 41-54. 